\title{
A Irmandade do Santíssimo Sacramento de Santo Estêvão de Alfama e a assistência à pobreza (1806-1820)
}

\author{
Isabel M. R. Mendes Drumond Braga[1]
}

\begin{abstract}
Resumo
Partindo de fontes manuscritas inéditas, produzidas pela irmandade do Santíssimo Sacramento de Santo Estêvão de Alfama, procuramos avaliar o papel da instituição na assistência à pobreza, analisando os regimentos e a prática quotidiana da atribuição de esmolas a determinados grupos de desvalidos. Em especial, procuramos indagar qual o peso da atividade assistencial aos pobres nas contas da instituição, visto que as confrarias se destacaram, em especial, pelas atividades ligadas ao culto e à assistência às almas dos confrades. Por outro lado, houve a preocupação de perceber quem eram os assistidos e quais os motivos que os tinham levado à categoria de pobres.
\end{abstract}

Palavras-chave: irmandade; pobreza; Santíssimo Sacramento.

\section{La Hermandad del Santísimo Sacramento de San Esteban de Alfama y la asistencia a la pobreza (1806-1820)}

\section{Resumen}

A partir de fuentes manuscritas inéditas, producidas por la Hermandad del Santísimo Sacramento de San Esteban de Alfama, buscamos evaluar el rol de la institución en la asistencia a la pobreza, analizando la normativa y la práctica cotidiana de la concesión de limosnas a ciertos grupos de desfavorecidos. En particular, se busca investigar cuál es el peso de la actividad asistencial a los pobres en las cuentas de la institución, pues las cofradías se destacaron en particular por las actividades relacionadas a la adoración y al cuidado de las almas de los miembros. Por otro lado, había la preocupación de percibir quién eran los asistidos y cuáles las razones que los habían conducido a la categoría de pobres.

Palabras clave: hermandad; pobreza; Santísimo Sacramento.

\section{The Confraternity of the Blessed Sacrament of Santo Estêvão de Alfama and the assistance to the poor (1806-1820)}

\begin{abstract}
Based on unpublished manuscript sources, produced by the Confraternity of the Blessed Sacrament of Santo Estêvão de Alfama, we aim to evaluate the institution's role in providing assistance to the poor, studying the regiments and the daily practice of assigning alms to certain groups of destitute people. Being confraternities specialized in activities linked to the cult and the souls of the deceased, we aim to investigate the impact of charitable activities on the institution's finances. Finally, there was a concern in verifying who were the beneficiaries and the motives that had them led to be included in the category of the poor. Keywords: brotherhood; poverty; Blessed Sacrament.

\section{La fraternité du Saint-Sacrement de Saint Étienne d'Alfama et l'assistance à la pauvreté (1806-1820)}

\section{Résumé}

Sur la base de sources manuscrites inédites produites par la fraternité de Saint Étienne d'Alfama, on a evalué du rôle de cette institution en lassistance à la pauvreté, en analysant les règlements et la pratique quotidienne de faire laumône à certains groups de pauvres. On a surtout remetté en question les poids dassistance aux pauvres dans les comptes delinstitution, car les confréries se sontspécialement mises en évidence grâce aux activités liées au culte et á lassistance aux âmes des confrères. D’autre part, il y a eu la préoccupation de percevoir qui étaient les assistés et les raisons qui les ont placé à la catégorie sociale des pauvres.

Mots-clés: fraternité; pauvetré; Saint-Sacrement.
\end{abstract}




\section{$\mathrm{O}$} Arquivo Histórico do Patriarcado de Lisboa guarda fundos documentais diversos, relativos a temáticas tão variadas como - e de entre outras - inventários de bens de eclesiásticos, processos de genere, exame de religiosas, causas do tribunal eclesiástico, visitas pastorais, a par de fontes relativas a conventos e a confrarias, uma boa parte dos quais em catalogação. ${ }^{1}$ Apesar da enorme riqueza do arquivo, a documentação ali depositada não tem despertado muito interesse entre os investigadores. No âmbito deste estudo, procuramos abordar as práticas assistenciais aos pobres levadas a efeito pela irmandade do Santíssimo Sacramento, com sede na igreja de Santo Estêvão de Alfama, em Lisboa, cujo espólio documental é composto por 46 séries e milhares de documentos. ${ }^{2}$ Atendendo ao objetivo da pesquisa, foram consultadas 12 séries das quais retiramos informações a par de mais algumas outras cujo exame se revelou infrutífero para a temática e a cronologia escolhidas.

Ao procurarmos conhecer a assistência aos desvalidos praticada pela confraria, deparamo-nos com uma questão base: qual o âmbito cronológico da abordagem, considerando-se que a irmandade esteve ativa entre os séculos XVI e XX. Na verdade, a consulta da documentação acabou por se revelar esclarecedora das possibilidades, considerando-se que só nos interessava a Época Moderna e tendo em conta que apenas restaram petições para obtenção de esmolas a partir de 1806. A escolha de 1820, o ano da Revolução Liberal e, concomitantemente, a data tradicional para o término do Antigo Regime, pareceu uma opção aceitável para determinar o final.

Como se sabe, em Portugal, as confrarias estão documentadas desde a Idade Média, remontando as origens a épocas anteriores. Eram associações leigas, embora pudessem contar com clérigos. A Igreja rapidamente as controlou, enquadrando-as nas paróquias e mosteiros, embora só fossem fiscalizadas pelos bispos no plano espiritual. A entrada dos confrades era voluntária, pública e celebrada por meio do juramento do compromisso - isto é, das normas ou estatutos pelos quais era regida -, o que implicava a inscrição no livro dos confrades e o pagamento de uma joia anual. Em princípio, essas agremiações estavam abertas a todos. Porém, o pagamento da quota anual implicava, desde logo, a exclusão dos mais carenciados. ${ }^{3}$ Constituíram um importante espaço de sociabilidade - na Época Medieval, ligada inclusivamente ao banquete, por ocasião da festa

\footnotetext{
'Um catálogo com alguns anos dá conta de ínfima parte da documentação do arquivo, tanto mais que a incorporação de documentos de várias paróquias de Lisboa tem sido uma constante. Cf. Isaías da Rosa Pereira, "Inventário Provisório do Arquivo da Cúria Patriarcal de Lisboa", Lusitania Sacra, tomo 9, Lisboa, 1972, p. 311-386.

${ }^{2}$ Agradecemos vivamente a competência, o incentivo e o apoio da Senhora Dr.a Teresa Ponces na disponibilização e na localização das séries desse fundo para a temática que nos interessava.

${ }^{3}$ Sobre as confrarias da Época Medieval, cf. Maria Ângela Beirante, Confrarias medievais portuguesas, Lisboa, [s.n.], 1990; Maria Helena da Cruz Coelho, "As confrarias medievais portuguesas: espaços de solidariedade na vida e na morte", In: Gobierno de Navarra, Departamento de Educacion y Cultura, Cofradías, Gremios, Solidaridades en la Europa Medieval, Navarra, Departamento de Educación y Cultura, 1992, p. 149-183.
} 
do orago, ${ }^{4}$ prática que posteriormente caiu em desuso com exceção das confrarias do Espírito Santo,$-{ }^{5}$ asseguraram as cerimônias fúnebres dos confrades e instituíram um meio de evidenciar integração e prestígio social. Assim se explica a presença de cristãos-novos nas fileiras dos confrades, ${ }^{6}$ apesar de algumas irmandades levantarem problemas ligados à limpeza de sangue ${ }^{7}$ o que foi alvo de crítica por parte de homens como D. Luís da Cunha. ${ }^{8}$ Por outro lado, saliente-se que algumas irmandades colocavam limites etários à adesão: ${ }^{9}$ as mulheres podiam integrar a maioria das confrarias ${ }^{10} \mathrm{e}$ as havia especificamente para negros ${ }^{11}$ e mulatos; ${ }^{12}$ no primeiro caso, em Portugal, e, no segundo caso, no Brasil. Ressalte-se ainda que,

\footnotetext{
${ }^{4}$ Maria Ângela Beirante, "Ritos alimentares em algumas confrarias portuguesas medievais", In: Territórios do Sagrado. Crenças e comportamentos na Idade Média em Portugal, Lisboa, Colibri, 2011, p. 185-197. ${ }^{5}$ Cf. Maria Paula Marçal Lourenço, "A casa da rainha e a Confraria do Espírito Santo de Alenquer (1645-1653)", Arquipélago. História, 2a série, vol. 5, Ponta Delgada, 2001, p. 651-668. Em Espanha, detectam-se casos de confrarias que, durante a Época Moderna, continuaram a servir comida em ocasiões festivas e também que ofereceram comida a pobres e presos em determinados momentos. Cf. María del Carmen Ansón Calvo; Fernando Manzano Ledesma; Nuria González Alonso, "Un ejemplo de sociabilidad gastronómica: las comidas de pobres y de fraternidad en las cofradías benaventanas en la Edad Moderna”, In: Francisco Núñez Roldán (coord.), Ocio y vida cotidiana en el mundo hispánico en la Edad Moderna, Sevilha, Universidade de Sevilha, 2007, p. 781-790. Cf. também Tomás Antonio Mantecón Movellán, Contrarreforma y religiosidad popular en Cantabria. Las cofradías religiosas, Santander, Publicaciones de la Universidad de Cantabria, 1990, p. 77.

${ }^{6}$ Pedro Penteado, "Confrarias portuguesas da Época Moderna: problemas, resultados e tendências de investigação", Lusitânia Sacra, 2a série, vol. 7, Lisboa, 1995, p. 28.

${ }^{7}$ Cf., por exemplo, Ana Cristina Araújo, "Corpos sociais, ritos e serviços religiosos numa comunidade rural. As confrarias de Gouveia na Época Moderna", Revista Portuguesa de História, tomo 35, Coimbra, 2001 2002, p. 291, relativamente à irmandade das Almas e de São Cosme de Alrote; ver também Maria João Pereira Coutinho; Sílvia Ferreira, "As irmandades da Igreja de São Roque. Tempo, propósito e legado", Revista Lusófona de Ciência das Religiões, n. 5-6, Lisboa, 2004, p. 201-216; Maria de Fátima Reis, "A Confraria da Avé-maria do Convento de São Bento de Santarém: afirmação e prestígio dos estatutos de limpeza de sangue", In: Luís Filipe Barreto; José Augusto Mourão (coords.), Inquisição Portuguesa. Tempo, razão e circunstância, Lisboa: Prefácio, 2007, p. 225-230. O mesmo também acontecia em Espanha. Cf., por exemplo, Manuel Moreno Valero, "Religiosidad popular en Córdoba en el siglo XVIII", In: Carlos Alvarez Santaló; María Jesús Buxó Rey; Salvador Rodriguez Becerra, La religiosidad popular: hermandades, romerías y santuarios, vol. 3, Barcelona, Anthropos, 1989, p. 489-499; Pedro Carasa Soto, Historia de la beneficencia en Castilla y Leon. Poder y pobreza en la sociedad castellana, Valladolid, Universidad de Valladolid, 1991, p. 144.

${ }^{8}$ D. Luís da Cunha considerou: "Não é só a Inquisição que pelo seu modo de processar, faz crescer o número dos cristãos-novos, mas também as irmandades e confrarias, e por isso se lhes deveria defender que nenhuma, sem excepção, tirasse inquirições de limpeza de sangue, porque eles vejam os que neles querem entrar; mas somente de vita et moribus, consultando sobre eles ao pároco, pois costumam infamar de cristãos-novos muito boas famílias que o não são, não deferindo aos estímulos da sua devoção". Cf. D. Luís da Cunha, Testamento político, Lisboa, Iniciativas Editoriais, 1978, p. 54. Sobre outras críticas a essa questão, cf. Didier Lahon, "Esclavage, confréries noires et pureté de sang au Portugal: XVIe-XVIII siècles", Lusitania Sacra, 2a série, vol. 15, Lisboa, 2003, p. 134-136 et passim.

${ }^{9}$ Georgina Silva dos Santos, Ofício e sangue. A Irmandade de São Jorge e a Inquisição na Lisboa Moderna, Lisboa, Colibri, 2005, p. 163-229; Idem, "A ferro e fogo: o enraizamento do ideário inquisitorial entre os oficiais mecânicos da Lisboa moderna", In: Maria da Graça A. Mateus Ventura (org.), O associativismo. Das confrarias e irmandades aos movimentos sociais contemporâneos, Lisboa, Colibri, 2006, p. 61; Susana Goulart Costa, Viver e morrer religiosamente. Ilha de São Miguel, século XVIII, Ponta Delgada, Instituto Cultural de Ponta Delgada, 2007, p. 272. Algumas dessas confrarias também colocavam impedimentos à entrada de doentes. ${ }^{10}$ Em alguns casos, pagando uma joia de entrada superior à dos homens. Cf. Guilhermina Mota, "A Irmandade da Senhora do Carmo do Marmeleiro - Mortágua (Primeira Metade do século XVIII)", Revista de História das Ideias, vol. 9, Coimbra, 1987, p. 279 et passim.

"Maria do Rosário Pimentel, Viagem ao fundo das consciências. A escravatura na Época Moderna, Lisboa, Colibri, 1995; Didier Lahon, op cit.

12/bidem; Larissa Viana, O idioma da mestiçagem. As irmandades de pardos na América Portuguesa, Campinas, Editora da UNICAMP, 2007.
} 
nas confrarias, a participação feminina era mais relevante do que a que se verificava entre as irmandades de brancos. ${ }^{13}$ Fora dos espaços continental e ultramarino, os portugueses que migraram para outras paragens não deixaram de fundar confrarias, uma boa parte delas sob invocação de Santo Antônio. Assim aconteceu em Roma ${ }^{14}$ e em diversas cidades de Espanha, tais como Cádis, Granada, Huelva, Madrid e Sevilha. ${ }^{15}$

As confrarias, na expressão de Pedro Carasa Soto, "pequenas igrejas dentro da igreja", ${ }^{16}$ poderiam ter objetivos diversos: caritativos, religiosos, penitenciais ou festivos, o que ditará a existência de uma tipologia diversificada: confrarias-associação (as penitenciais e profissionais) e confrarias-instituição (as que se dedicavam à gestão do culto e do patrimônio), para Maurice Agulhon; ${ }^{17}$ abertas, fechadas ou de adscrição automática, se tivermos em conta as condições de acesso, ou ainda horizontais (as que evidenciam a configuração social) e verticais (as que pretendem iludir a configuração social, negando-a simbolicamente), refletindo a categoria social dos irmãos na perspectiva de Luís Maldonado; ${ }^{18}$ ou ainda gremiais (agregam os da mesma profissão), sacramentais (conferem ajuda mútua) e caritativas (dedicação a um aspecto específico da caridade), para Saborit Badenes. ${ }^{19}$ De qualquer modo, as tipologias possíveis não se esgotam aqui. ${ }^{20}$

\footnotetext{
${ }^{13}$ Luciano Figueiredo, O avesso da memória. Cotidiano e trabalho da mulher em Minas Gerais no século XVIII, 2. ed., Rio de janeiro, José Olympio, 1999, p. 152-157. Sobre a presença feminina nas confrarias portuguesas, cf., por exemplo, Laurinda Abreu, “Confrarias e irmandades em Setúbal: redes de sociabilidade e poder", In: I Congresso Internacional do Barroco. Actas, vol. 1, Porto, Reitoria da Universidade do Porto; Governo Civil do Porto, 1991, p. 12.

${ }^{14}$ Maria de Lurdes Pereira Rosa, "L'ospedale della nazione portoghese di Roma, sec. XIV-XX. Elementi di storia istituzionale e archivistica", Mélanges de l'Ecole Française de Rome, Italie et Méditerranée, tomo 106, n. 1, Roma, 1994, p. 73-128.

${ }^{15} J u a n$ Ignacio Pulido Serrano, "Hermandades portuguesas fuera de Portugal (siglos XVI-XVIII)", In: O associativismo. Das confrarias e irmandades aos movimentos sociais contemporâneos, Lisboa, Colibri, 2006, p. 29-49.

${ }^{16}$ Pedro Carasa Soto, Historia de la beneficencia en Castilla y Leon. Poder y pobreza en la sociedad castellana, Valladolid, Universidad de Valladolid, 1991, p. 142

${ }^{17}$ Maurice Agulhon, Pénitents et franco-maçons de lancienne Provence: essai sur la sociabilité méridionale, Paris, Fayard, 1984

${ }^{18}$ Apud Pedro Penteado, "Confrarias", In: Carlos Moreira de Azevedo (coord.), Dicionário de História Religiosa em Portugal, vol. A-C, Lisboa, Círculo de Leitores, 2000, p. 459-470 (em especial, p. 460).

${ }^{19}$ Pere Saborit Badenes, "Las cofradías. Estudio del significado de las cofradías a través de las del Alto Palencia", Estudis. Revista de Historia Moderna, n. 16, Valencia, 1990, p. 141-142.

${ }^{20}$ Cf. Amalia García Pedraza; Miguel Luis López Muñoz, "Cofarías y moriscos en la Granada del siglo XVI (1500-1568)", In: Antonio Mestre Sanchís; Enríque Giménez López (coords.), Disidencias y exilados en la España Moderna, Alicante, Universidad de Alicante, 1997, p. 377-392; Álvaro Aragón Ruano; Xabier Alberdi Londibe, "El proceso de institucionalización de las cofradías guipuzcoanas durante la Edad Moderna: cofradías de Mareantes y de Podavines", Vasconia, vol. 30, Donostia, 2000, p. 205-222; Alexis Fontbonne, "Les confréries capitulaires du XIle au XVe siècle. Une proposition pour la typologie des confréries: de l'institutionnel au relationnel", Confraternitas, vol. 18, n. 2, Toronto, 2007, p. 3-16; Candelaria Castro Pérez; Mercedes Calvo Cruz; Sonia Granado Suárez, "Las cofradías en la institución parroquial, siglos XVII-XVIII. Una aplicación al señorío episcopal de la Villa de Agüimes, Canarias (España)", Procesos Históricos, vol. 13, Bogotá, 2008, p. 6-7.
} 
Algumas irmandades medievais foram absorvidas pelas Misericórdias, ${ }^{21} \mathrm{o}$ que não implicou falta de criação de muitas na Época Moderna, ${ }^{22}$ pois verificouse sempre um elevado número de confrarias por paróquia. Dados compilados por Isabel dos Guimarães Sá apontam, para o século XVIII, mais de 80 confrarias nas seis freguesias de Braga, 32 em quatro paróquias de Aveiro e 215 em 45 paróquias de Vila Real. ${ }^{23}$ Outros casos posteriores se podem juntar. Por exemplo, Maria Antónia Lopes, ao reunir informações sobre a matéria, referiu que, em 1792, estavam ativas na diocese de Viana 759 confrarias em 274 paróquias. ${ }^{24}$

As confrarias contaram-se entre os
mecanismos de disciplinamento social
incrementados após o Concílio de Trento

As confrarias sob a invocação do Santíssimo Sacramento, tal como as do Rosário ${ }^{25}$ e das Almas, foram impulsionadas após a realização do Concílio de Trento. Para Mantecón Movellán, independentemente da invocação das confrarias, um dos principais interesses da atuação das mesmas, a par da ajuda à pobreza e do acompanhamento dos mortos, foi a reforma dos costumes atra-

${ }^{21}$ Maria Antónia Lopes, Protecção social em Portugal na Idade Moderna. Guia de estudo e investigação, Coimbra, Imprensa da Universidade de Coimbra, 2010, p. 107.

22Sobre confrarias da Época Moderna na Europa, cf., além da bibliografia anteriormente citada, Anastacio Alemán Illán, "Sociabilidad, muerte y religiosidad popular. Las cofradías de Murcia durante el siglo XVIII”, In: Carlos Álvarez Santaló; María Jesús Buxó Rey; Salvador Rodriguez Becerra (coords.), La religiosidad popular: vida y muerte - la imaginación religiosa, vol. 2. Barcelona, Anthropos, 1989, p. 361-383. Sobre as confrarias portuguesas, cf. Maria Fernanda Enes, "As confrarias do Santíssimo Sacramento e das Almas no âmbito da cultura barroca (um caso na Diocese de Angra)", In: I Congresso Internacional do Barroco. Actas, vol. 1, Porto, Reitoria da Universidade do Porto; Governo Civil do Porto, 1991, p. 275-289; Laurinda Abreu, "Confrarias e irmandades: a santificação do quotidiano", In: Maria Helena Carvalho dos Santos (coord.), A Festa. Comunicações apresentadas ao VIII Congresso Internacional, vol. 2, Lisboa, Sociedade Portuguesa de Estudos do Século XVIII; Universitária Editora, 1992, p. 429-442; Maria Marta Lobo de Araújo, "A Confraria de São Pedro da Gafanhoeira entre a aurora e o entardecer", Cadernos do Noroeste, Série História, vol. 15, n. 1-2, Braga, 2001, p. 359-378; Idem, A Confraria do Santíssimo Sacramento do Pico de Regalados (1731-1780), Vila Verde, ATAHCA, 2001; Idem, "A ajuda aos pobres nas Confrarias de Nossa Senhora da Guia e do Espírito Santo de Ponte de Lima (séculos XVI a XIX)", Bracara Augusta, vol. 50, n. 104-105, Braga, 2001-2002, p. 441-468; Idem, A Confraria de Nossa Senhora do Porto de Ave. Um Itinerário sobre a Religiosidade Popular do Baixo Minho, Taíde, Póvoa de Lanhoso, Confraria de Nossa Senhora de Porto de Ave, 2006; Maria de Fátima Reis, Santarém no tempo de D. João V. Administração, Sociedade e Cultura, Lisboa, Colibri, 2004; Aníbal Barreira, "A Irmandade de Nossa Senhora do Terço e Caridade da Cidade do Porto - evolução da entrada de irmãos (1766-1927)", Revista Portuguesa de História, tomo 36, vol. 2, Coimbra, 2002-2003, p. 733-83; Vitor Paulo Pereira, A Confraria do Divino Espirito Santo de Coura. Origens, diáspora e expansão, [s...], [s.n.], 2009; Maria Ângela Beirante, As antigas Confrarias da Vila de Cabeção: espelho da sua vida social e religiosa, Lisboa, Colibri, 2011.

${ }^{23}$ Isabel dos Guimarães Sá, "As confrarias e as misericórdias", In: Nuno Gonçalo Monteiro; César de Oliveira, História dos municípios e do poder local. Dos finais da Idade Média à União Europeia, Lisboa, Círculo de Leitores, 1995, p. 55-56.

${ }^{24}$ Maria Antónia Lopes, op cit., 2010, p. 105.

${ }^{25}$ Sobre as confrarias do Rosário, sobretudo ligadas aos dominicanos, cf. Saul António Gomes, "Notas e documentos sobre as confrarias portuguesas entre o fim da Idade Média e o século XVII: o protagonismo dominicano de Santa Maria da Vitória", Lusitania Sacra, 2a série, tomo 7, Lisboa, 1995, p. 89-150. Sobre as confrarias do Rosário em Espanha, cf. Tomás Antonio Mantecón Movellán, Contrarreforma y religiosidad popular en Cantabria. Las cofradías religiosas, Santander, Publicaciones de la Universidad de Cantabria, 1990, p. 55-57 et passim. 
vés de propostas de modos de vida de acordo com as decisões conciliares, o que favoreceu a paz vicinal. ${ }^{26}$ Isto é, as confrarias contaram-se entre os mecanismos de disciplinamento social incrementados após o Concílio. ${ }^{27}$

No caso das confrarias do Santíssimo Sacramento, constituíram uma tentativa de resposta à crise teológica levantada pelos chamados protestantes quando os mesmos negaram a presença de Deus na eucaristia. Para João Francisco Marques, teria sido o modelo da arquiconfraria instituída no convento dominicano de Santa Maria Sopra Minerva (Roma), aprovada por Paulo III, em 1539, a repercutir-se pela Cristandade.$^{28}$ Visando em especial a solenização do culto, essas instituições investiram muito particularmente nas celebrações litúrgicas ligadas aos mistérios de Cristo, tornando-se o ciclo da Páscoa o mais relevante. No entanto, algumas dessas irmandades foram criadas anteriormente ou em data muito próxima desses eventos, o que demonstra a não influência dessa realidade.

De fato, a do Santíssimo Sacramento, da igreja de Santo Estêvão de Alfama, foi instituída por volta de 1540, atendendo a que em junho desse ano teve autorização para colocar uma caixa de esmolas na igreja.$^{29}$ Nessa centúria, a mesma igreja albergará outras confrarias: Nossa Senhora da Conceição, Nossa Senhora do Paraíso, Espírito Santo e Jesus. ${ }^{30}$ Poucos anos depois, em 1551, Cristóvão Rodrigues de Oliveira fez saber que a paróquia sediava as confrarias do Santo Sacramento, de Nossa Senhora da Conceição, de São Sebastião e de

\footnotetext{
${ }^{26}$ Tomás Antonio Mantecón Movellán, Contrarreforma y religiosidad popular en Cantabria. Las cofradías religiosas, Santander, Publicaciones de la Universidad de Cantabria, 1990.

${ }^{27}$ Sobre essa questão, cf. Winfried Schulze, "Il concetto di 'disciplinamento sociale nella prima Età Moderna' in Gerhard Oestreich", Annali dell'Istituto Storico Italo-Germanico in Trento, vol. 18, Bolonha, 1992, p. 371-411; Wolfgang Reinhard, “Disciplinamento sociale, confessionalizzazione, modernizzazione. Un discurso storiografico", In: Paolo Prodi; Carla Penuti, Disciplina dell'Anina, Disciplina del Corpo e Disciplina della Società tra Medioevo ad Età Moderna, Bolonha, Società Editrice II Mulino, 1994, p. 101-123; Heinz Schilling, "Chiese confessionali e disciplinamento sociale. Un bilancio provvisorio della ricerca storica", In: Ibidem, p. 125-160; Idem, "L'Europa delle chiese e delle confessioni”, In: Maria Antonietta Visceglia (dir.), La radici storiche dell' Europa. L'Età Moderna, Roma, Viella, 2007, p. 69-81; Adriano Prosperi, "Riforma cattolica, contrariforma, disciplinamento sociale", In: Gabriele De Rosa; Tulio Gregory (dirs.), L'Età Moderna, Roma; Bari, Laterza, 1994, p. 3-48; Idem. Tribunali della coscienza. Inquisitori, confessori, missionari, Turim, Einaudi, 1996; Federico Palomo, “'Disciplina christiana': apuntes historiográficos en torno a la disciplina y el disciplinamento social como categorias de la historia religiosa de la Alta Edad Moderna", Cuadernos de Historia Moderna, n. 18, Madrid, 1997, p. 119-136; Elena Brambilla, La giustizia intolerante. Inquisizione e Tribunali Confessionali in Europa (secoli IV-XVIII), Roma, Carocci Editore, 2006. No que se refere concretamente às mulheres, cf. María Luisa Candau Chacón, "Disciplinamiento católico e identidad de género. Mujeres, sensualidad y penitencia en la España Moderna", Manuscrits, vol. 25, Madrid, 2007, p. 21-237.

${ }^{28}$ João Francisco Marques, "A renovação das práticas devocionais", In: Carlos Moreira de Azevedo (dir.), História Religiosa de Portugal: Humanismo e Reforma, vol. 2, Lisboa, Círculo de Leitores, 2000, p. 568-570. Cf. também Franquelim Neiva Soares, "A Confraria do Santíssimo Sacramento de S. Miguel das Marinhas", Cadernos do Noroeste, Série História, vol. 3, Braga, 2003, p. 223 et passim.

${ }^{29}$ Isaías da Rosa Pereira, Documentos para a história do patriarcado de Lisboa. Visitações (1540-1561); Livro de Aniversários e Tombos de Bens (século XV) da Freguesia de Santo Estêvão de Alfama, Lisboa, Vida Católica, 1993, p. 12; 17

${ }^{30}$ A igreja de Santo Estêvão de Alfama, originariamente um templo do século XII, foi objeto de reconstruções em 1316 e 1543, completamente reedificada em 1733 e parcialmente refeita após o terremoto de 1755. Nos anos 30 do século XIX, foi restaurada. Cf. Gustavo Couto, Historia da Egreja de Santo Estevam de Lisboa, Lisboa, Tipografia do Comércio, 1927, p. 10; Sidónio Miguel, A Igreja e o Sitio de Santo Estêvão de Alfama, Lisboa, [s.n.], 1939, p. 14; Portugal. Património Cultural. Disponível em: <http://www.igespar.pt/pt/patrimonio/ pesquisa/geral/patrimonioimovel/detail/70627>. Acesso em: 1 mar. 2012.
} 
Santo Estêvão, as quais rendiam 165 cruzados. ${ }^{31}$ Robustecendo os cuidados com o culto, sabe-se que, a 24 de março de 1670, passaram para a confraria do Santíssimo Sacramento a obrigação dos paramentos da capela-mor e da sacristia e a de três lâmpadas acesas, dando-se aos irmãos, mulheres e filhos 12 covas na igreja. ${ }^{32}$

Detenhamo-nos na assistência material ${ }^{33}$ concedida aos pobres praticada pela confraria do Santíssimo Sacramento de Santo Estêvão de Alfama, uma irmandade aberta e sacramental, composta por leigos e eclesiásticos, presumivelmente com muita gente ligada às atividades marítimas. ${ }^{34}$ Quantas pessoas, quais, por que motivos e de que maneira foram objeto de caridade, eis algumas perguntas para as quais importa encontrar respostas. Concomitantemente, temos como propósito perceber até que ponto a confraria se empenhava na ajuda material concedida aos desvalidos.

Comecemos por tornar claro os conceitos de pobre e de pobreza, de acordo com a época, uma vez que são categorias relevantes. Cite-se Rafael Bluteau que, de forma simples e realista, entende por pobre todo aquele que não tem o necessário para o sustento e que apresenta como sinônimos infeliz, desgraçado e triste. ${ }^{35}$ Passemos para a atualidade e vejamos a teorização de Jean-Pierre Gutton, em texto já com alguns anos, mas que continua operativo. Para o autor, era pobre todo aquele que vivia apenas do seu trabalho porque, a qualquer momento, podia tornar-se indigente. Atendendo à total ausência de meios de segurança social, quem não tinha bens — ou seja, a esmagadora maioria da população - e simultaneamente não trabalhava era, naturalmente, pobre e, consequentemente, cliente da caridade particular e da caridade institucional. O autor não esqueceu os mecanismos através dos quais a sociedade produzia pobres e os julgava, além de se deter no que denominou o vasto vocabulário da miséria. Finalmente, optou por tipificar três categorias de pobres, a saber,

\footnotetext{
${ }^{31}$ Cristóvão Rodrigues de Oliveira, Lisboa em 1551. Sumário, apresentação e notas de José da Felicidade Alves, Lisboa, Livros Horizonte, 1987, p. 32-33.

32Sidónio Miguel, A Igreja e o Sítio de Santo Estêvão de Alfama, Lisboa, [s.n.], 1939, p. 14.

${ }^{33}$ Apesar de a assistência espiritual ser muito relevante em qualquer confraria, inclusive essa, a opção foi o tratamento da ajuda material corporizada nas esmolas monetárias em detrimento de todo o apoio espiritual, incluindo o que se ligava às cerimônias fúnebres e aos cuidados com a alma, matérias que ficaram fora deste estudo.

${ }^{34}$ Não conseguimos apurar a esmagadora maioria das atividades a que se dedicavam os confrades. Contudo, os exemplos aleatórios encontrados para a cronologia em estudo permitem presumir o que se afirmou. Sobre confrarias com elevadas percentagens de eclesiásticos, cf. Paula Alexandra de Carvalho Sobral Gomes, Oficiais e confrades em Braga no Tempo de Pombal. Contributos para o Estudo do Movimento e Organização Confraternal Bracarenses no século XVIII, Dissertação de mestrado, Universidade do Minho, Braga, 2002, p. 165 et passim. Sobre as confrarias de adscrição automática, cf. Paulo Drumond Braga, “Uma confraria da Inquisição: a Irmandade de São Pedro Mártir (breves notas)", Arquipélago. História, 2a série, vol. 2. Ponta Delgada, 1997, p. 449-458; Ricardo Pessa de Oliveira, "Para o estudo da Irmandade de São Pedro Mártir no final do século XVIII", In: IV Congresso Histórico de Guimarães “Do Absolutismo ao Liberalismo". Actas, vol. I, Guimarães, Câmara Municipal de Guimarães, 2009, p. 509-530.

${ }^{35}$ Rafael Bluteau, Vocabulario portuguez e latino, tomo 6, Lisboa, Oficina de Pascoal da Silva, 1720, p. 557. Dados elaborados para outros espaços não diferem. Cf. Vittorio Beonio Brocchiero, "Miserabili e vagabondi", In: Laura Barletta (dir.), Vita privata e scena pubblica. Vivere, abitare, viaggiare in Età Mosderna, Milão, Encyclomedia Publishers, 2010, p. 121-124.
} 
doentes, velhos e viúvos, fazendo notar que a maioria dos carenciados pertencia ao sexo feminino. ${ }^{36}$

Ao longo dos tempos, a irmandade do Santíssimo Sacramento de Santo Estêvão de Alfama foi tendo vários estatutos, todos com capítulos afetos à ajuda a ser prestada aos desvalidos. Em 1806, quando começaram as petições de esmolas em estudo, estavam em vigor os de 1805, os quais foram confirmados por D. João VI, a 28 de maio de $1816 .{ }^{37}$ A 18 de novembro de 1804, foi decidido que importava convocar a irmandade em junta grande para se ouvir o novo compromisso, o que veio a acontecer a 9 de dezembro seguinte, como se verifica pelo livro de acórdãos, termos e atas. ${ }^{38}$ Esses estatutos vieram a substituir os de agosto de 1749, confirmados pelo cardeal patriarca, a 17 de janeiro de $1750 .{ }^{39}$ No que se refere às ajudas a conceder aos pobres, as determinações presentes nos dois textos são diferentes, porém, em qualquer dos casos, revelam cuidado com a matéria.

O regimento setecentista dedicou o capítulo 23 ao socorro dos pobres:

$1 .^{\circ}$ Os verdadeiros ofícios de bons irmãos, he tratarem de acodir huns aos outros em suas misérias de que Deus Nosso senhor muito se agrada. Logo que algum irmão adoecer a Meza o mandara vizitar pello procurador o qual saberá se necessita de alguma couza e o admoestara se comfece e sacramente, propondo-lhe o bem de sua salvação. 2. ${ }^{\circ}$ Sendo pobre com doensa prolongada e não tendo que gastar o juiz e os oficiaes da Meza o proverão do que lhes for mais precizo procurando socorrelo o melhor que puder ser. 3. ${ }^{\circ}$ Se algum irmão cahir em pobreza que não possa satisfazer as prezidencias constando da sua empossibilidade não só o livrara a Meza desta obrigasão mas ainda o socorrerá com aquilo que puder o mesmo com as irmans e viúvas dos nossos irmãos vivendo onestamente no estado de viúva por que cazado não gozarão da Irmandade e seos sufrágios. $4 .^{\circ}$ Tambem estando algum irmão prezo na cadea sendo a prizão por cauza onesta de que a irmandade se não possa afrontar de o ter por irmão, tendo a Meza noticia de que haja mister alguma diligencia pessoal de o por em sua liberdade ordenará ao procurador a fasa com todo o cuidado e por serviço de Nosso Senhor athe com effeito ser solto. ${ }^{40}$

No capítulo 9 do compromisso de 1805 (Figura 1), podemos ler:

\footnotetext{
 d'Edition Les Belles Lettres, 1971, p. 1-46. Mais recentemente, outros autores também se detiveram na conceptualização de pobre e de pobreza. Cf., para Portugal, Maria Antónia Lopes, Pobreza, assistência e controlo social. Coimbra (1750-1850), vol. 1, Viseu, Palimage Editores, Centro de História da Sociedade e da Cultura, 2000, p. 13-17 (sobre os pobres nos discursos das elites, cf. p. 35-163); Idem, Protecção social em Portugal na Idade Moderna. Guia de estudo e investigação, Coimbra, Imprensa da Universidade de Coimbra, 2010, p. 19-20. António Manuel Hespanha, Imbecillitas. As bem-aventuranças da inferioridade nas sociedades de Antigo Regime, São Paulo, Annablume, 2010, p. 233-234. Para outros espaços, cf. Patricia Crawford, Parents of poor children in England: 1580-1800, Oxford, Oxford University Press, 2010, p. 6-9.

${ }^{37}$ Lisboa, Arquivo Histórico do Patriarcado de Lisboa (AHPL), PLSB36/ISS/01/003.

38/bidem, PLSB36/ISS/03/004, fls. 43-43v.

39/bidem, PLSB36/ISS/O1/002.

40/bidem, PLSB36/ISS/01/002
} 


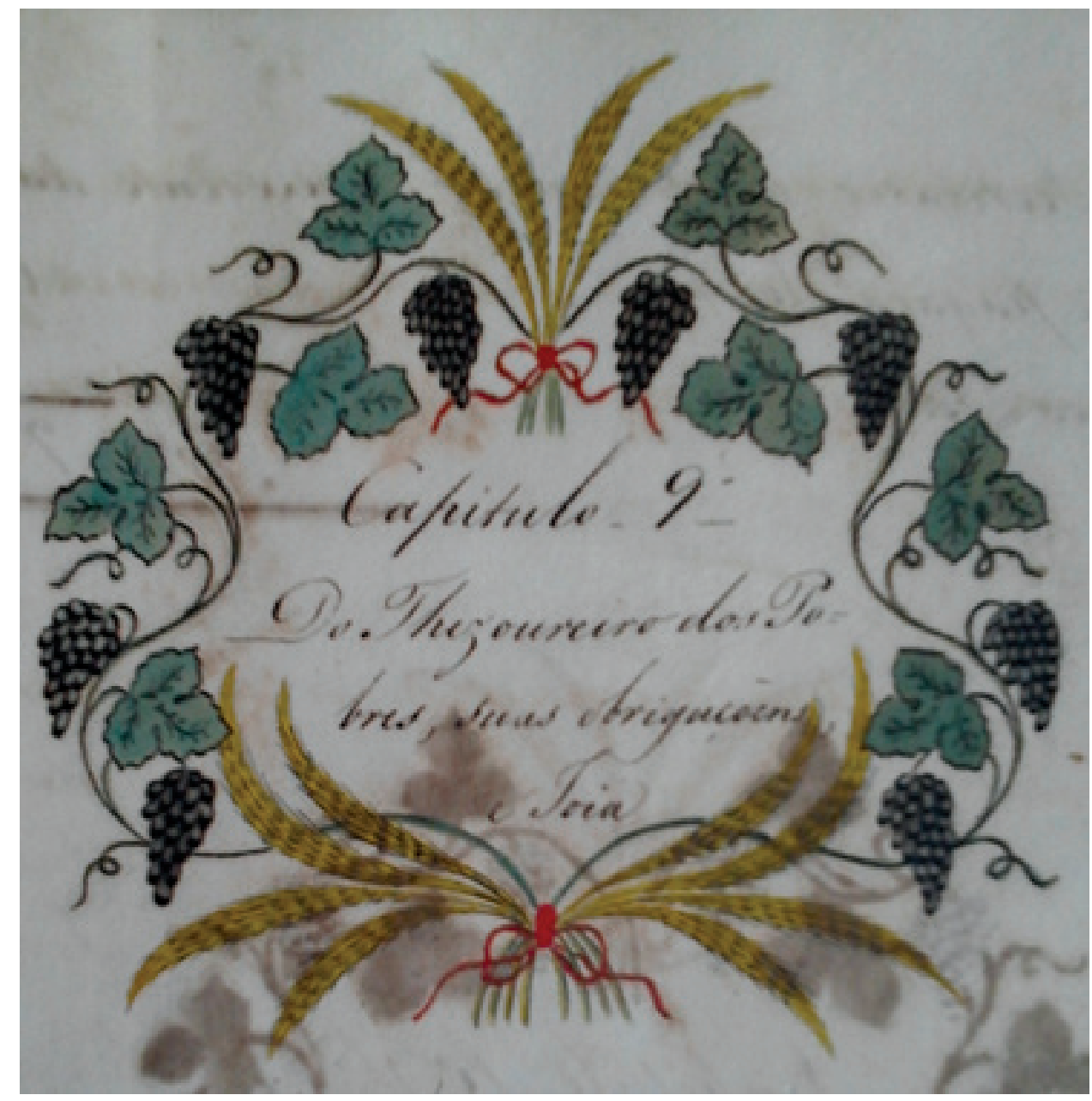

Figura 1. Pormenor da página aquarelada do capítulo 9 "Do Thezoureiro dos Pobres, suas obrigações, e Joia”, do compromisso de 1805. Lisboa, Arquivo Histórico do Patriarcado de Lisboa, PLSB36/ISS/01/003.

\$1 O tesoureiro dos pobres terá obrigação de examinar a necessidade dos irmãos pobres principalmente quando estes requerem por petição esmola à Mesa, pois antes de apresentar à Mesa estes requerimentos saberá do irmão presidente do distrito se é verdadeira a actual necessidade. $\S 2$ Terá a chave do cofre dos irmãos pobres aonde estará todo o dinheiro a elles pertencente e este se não abrira sem que seja em acto de Mesa ou conferência, cobrara dos Irmãos, tanto da Mesa como dos novos, as jóias pertencentes a este cofre como se declara nos capítulos competentes. ${ }^{41}$

Mais à frente, no capítulo 15,

${ }^{41}$ Lisboa, AHPL, PLSB36/ISS/01/OO3. Estatutos e Compromisso por onde se há de reger a Irmandade do Santíssimo Sacramento da Parrrochial Igreja de Santo Estêvão desta Cidade de Lisboa. Feito no anno de 1805, cap. 9. 
§ 5 se algum irmão cair em pobreza e que não possa pagar as presidências não só será aliviado desta obrigação, mas será socorrido com o que se poder remediar e o mesmo se praticara com as irmãs viúvas vivendo no dito estado. ${ }^{42}$

Quais as fontes de receitas da confraria e que quantias foram gastas com o socorro aos desvalidos? No cumprimento das determinações estatutárias, as receitas eram provenientes do recebimento das joias de entradas dos irmãos e das joias dos que desempenhavam cargos, a saber: o juiz pagaria 3.200 réis, os dois assistentes do juiz, 1.600 (cada um), o primeiro secretário, 1.600, o segundo, 1.200, tal como os conselheiros, o tesoureiro dos pobres, 800, tal como os irmãos, e os mordomos, 480 réis. ${ }^{43} \mathrm{~A}$ irmandade possuía livros de receita e de despesa do Cofre dos Pobres, nos quais registava as entradas e as saídas de numerário.

Com base na Tabela 1, podemos verificar que, em matéria assistencial, as contas da confraria estiveram sempre bem. Com exceção dos anos de $1818 \mathrm{e}$ de 1819, o saldo foi sempre positivo e, entre 1806 e 1820, o saldo positivo acumulado ascendeu a 63.100 réis, atendendo a que ignoramos o que antes de 1806 se acumulara. Ou seja, a ajuda monetária prestada aos confrades pobres não constituiu um problema, embora desconheçamos a existência de eventuais petições cuja resposta não tenha sido positiva.

Para melhor percebermos as contas da confraria, observemos as restantes receitas e despesas e calculemos a parte que coube à assistência material prestada aos pobres. Tal como em outras instituições congêneres, ${ }^{44}$ a confraria do Santíssimo Sacramento de Santo Estêvão de Alfama tinha fontes diversificadas de receitas, a saber: recebimento de joias, montantes obtidos nos peditórios, legados, quantias auferidas pela realização de batizados, rendas, foros e juros cobrados em resultado da prática de empréstimos monetários. Por seu lado, as despesas gerais abrangiam as quantias gastas com a celebração de missas, as demandas, as obras, os ordenados dos andadores, a cera, os paramentos, os sermões e, sobretudo, as festividades da Semana Santa e do Corpo de Deus.

\footnotetext{
42Lisboa, AHPL, PLSB36/ISS/01/003. Estatutos e Compromisso por onde se há de reger a Irmandade do Santíssimo Sacramento da Parrrochial Igreja de Santo Estêvão desta Cidade de Lisboa. Feito no anno de 1805, cap. 9.

43/bidem, cap. 15

${ }^{44} \mathrm{Cf}$., por exemplo, Pere Saborit Badenes, "Las cofradías. Estudio del significado de las cofradías a través de las del Alto Palencia”, Estudis. Revista de Historia Moderna, n. 16, Valencia, 1990, p. 156; Belarmino Afonso, "Confrarias e mentalidade barroca", In: I Congresso Internacional do Barroco. Actas, vol. 1, Porto, Reitoria da Universidade do Porto; Governo Civil do Porto, 1991, p. 32-33; Maria Fernanda Enes, "As confrarias do Santíssimo Sacramento e das Almas no âmbito da cultura barroca (um caso na Diocese de Angra)", In: Ibidem, p. 285-294; Maria Marta Lobo de Araújo, A Confraria do Santíssimo Sacramento do Pico de Regalados (1731-1780), Vila Verde, ATAHCA, 2001, p. 109-126; Idem, A Confraria de Nossa Senhora do Porto de Ave. Um Itinerário sobre a Religiosidade Popular do Baixo Minho, Taíde, Póvoa de Lanhoso, Confraria de Nossa Senhora de Porto de Ave, 2006, p. 135-215; Susana Goulart Costa, Viver e morrer religiosamente. IIha de São Miguel, século XVIII, Ponta Delgada, Instituto Cultural de Ponta Delgada, 2007, p. 275; 285-287. Em algumas confrarias nas zonas rurais da Ilha de São Miguel, as joias e as anuidades eram pagas em cereal.
} 
Tabela 1. Receitas e despesas (em réis) do Cofre dos Pobres (1806-1820)

\begin{tabular}{lcccc}
\hline Ano & Receita & Despesa & Saldo & Saldo acumulado \\
\hline 1806 & 30.930 & 29.800 & 1.130 & - \\
\hline 1807 & 20.010 & 17.200 & 2.810 & 3.940 \\
1808 & 23.610 & 18.800 & 4.810 & 8.750 \\
\hline 1809 & 27.210 & 16.640 & 10.570 & 19.320 \\
1810 & 29.210 & 20.120 & 9.090 & 28.410 \\
1811 & 35.320 & 26.240 & 9.080 & 37.490 \\
1812 & 34.290 & 24.720 & 9.570 & 47.060 \\
1813 & 29.490 & 25.760 & 3.730 & 50.790 \\
1814 & 30.610 & 29.920 & 690 & 51.480 \\
1815 & 34.605 & 26.800 & 7.805 & 59.285 \\
1816 & 40.285 & 28.560 & 11.725 & 71.010 \\
1817 & 34.525 & 33.600 & 925 & 71.935 \\
1818 & 22.045 & 30.240 & -8.195 & 63.740 \\
1819 & 11.600 & 12.400 & -800 & 62.940 \\
1820 & 17.280 & 17.120 & 160 & 63.100 \\
\hline
\end{tabular}

Fonte: dados constantes dos livros de receita e despesa do Cofre dos Pobres. Cf. Lisboa, Arquivo Histórico do Patriarcado de Lisboa, PLSB36/ISS/33/0O2, fls. 24-45, e Lisboa, Arquivo Histórico do Patriarcado de Lisboa, PLSB36/ISS/33/003, fls. 49-64.

Note-se que as festas religiosas, em algumas confrarias, absorviam a quase totalidade das receitas, ${ }^{45}$ o que não acontecia na do Santíssimo Sacramento de Santo Estêvão de Alfama. Sabe-se, por exemplo, que nos anos de 1818 a 1820, os gastos com a celebração das festividades da Semana Santa, a mais importante festa do calendário litúrgico para os confrades, ascenderam a 104.250, $96.310 \mathrm{e}$ 98.430 réis, ${ }^{46}$ o que significou, $8,4,12,7$ e 13,6\%, respectivamente, das despesas gerais. Mesmo tendo em conta que outros momentos de festa, nomeadamente pelo Corpo de Deus, eram igualmente motivo de celebração, em que se gastava cerca de metade ou pouco mais do que metade do que se despendia com as festas da Semana Santa, e sabendo-se igualmente que o culto quotidiano implicava gastos com cera, azeite e algumas peças de prata ou de metais não nobres que eram comprados ou com objetos de limpeza e arranjos frequentes, as verbas despendidas nessa rubrica que não representavam a totalidade dos gastos eram muito significativas. Mesmo assim, havia ainda quantias destinadas às celebrações de missas, às pregação de sermões, aos ordenados dos andadores e do procurador, aos gastos com demandas, aos impostos sobre as propriedades rústicas e urbanas, às lavagens de roupa, à aquisição de capas para os confrades e a um vasto grupo de outras despesas miúdas, muitas vezes não descriminadas (Tabela 2).

\footnotetext{
${ }^{45}$ Laurinda Abreu, "Confrarias e irmandades em Setúbal: redes de sociabilidade e poder", In: I Congresso Internacional do Barroco. Actas, vol. 1, Porto, Reitoria da Universidade do Porto; Governo Civil do Porto, 1991, p. 433

${ }^{46}$ Lisboa, AHPL, PLSB36/ISS/38/docs. 326, 338 e 350.
} 
Tabela 2. Despesas (em réis) realizadas com as celebrações da Semana Santa de 1818

\begin{tabular}{lc} 
Bens e serviços & Quantia \\
\hline 5 sermões nos domingos da quaresma & 24.000 \\
\hline sermões na sexta-feira à noite e no domingo de Páscoa & 12.800 \\
\hline Colegiada & 4.800 \\
Mal mitos no domingo de ramos & 16.660 \\
\hline Palmas & 2.400 \\
\hline Sege para o pregador & 1.840 \\
\hline 4 feixes de rosmaninho & 1.260 \\
Guarda para a procissão & 8.000 \\
Música com os tamboretes & 7.360 \\
Vinho, doces e licor para a guarda dos pregadores & 7.910 \\
\hline Sacristão & 480 \\
Varredores & 600 \\
\hline Bilhas para sábado de aleluia & 6.220 \\
\hline Limpeza das 4 lâmpadas & 3.200 \\
Propina do andor & 720 \\
\hline Propina de 2 dúzias de capas e 1 cruz & 1.200 \\
\hline Propina de $1 \frac{1}{2}$ de capas de S. Vicente & 600 \\
\hline Propina do ornamento roxo dos Remédios & 600 \\
\hline Carretos de moços & 1.300 \\
\hline Lavagem da igreja e mais despesas como consta do rol que deu José Caetano & 2.300 \\
\hline Total & 104.250 \\
\hline
\end{tabular}

Voltando às receitas e às despesas gerais, se às mesmas juntarmos as receitas e as despesas do cofre dos pobres, poderemos calcular a percentagem que a irmandade destinava ao socorro dos confrades desvalidos e tentar perceber até que ponto a assistência material era ou não uma prioridade.

Como se pode ver pela Tabela 3, as receitas gerais foram sempre superiores às despesas, permitindo a existência de saldos positivos todos os anos. Se a esses números juntarmos as quantias das receitas e despesas do cofre dos pobres, podemos verificar que estas representaram, em média, 2,6\% do total, sendo a oscilação anual pouco significativa. Note-se, contudo, que esses valores ficaram bastante aquém do que se gastava só com as celebrações da Semana Santa, o que desde já nos torna claro que a assistência material aos confrades não era de modo nenhum uma das prioridades da confraria.

O número de beneficiários de esmolas variou muito ao longo dos anos, havendo pessoas que foram contempladas em diversos anos sucessivos. Foi frequente, por morte do confrade, a viúva passar a confreira, em muitos casos, assentando-se como pobre nos livros. Se alguns apenas pretenderam ficar isentos do pagamento total ou parcial das presidências - ou seja, das anuidades - , outros solicitaram esmolas efetivas, situações que também se detectaram em outros universos. ${ }^{47}$

\footnotetext{
${ }^{47}$ Maria Marta Lobo de Araújo, "A ajuda aos pobres nas Confrarias de Nossa Senhora da Guia e do Espírito Santo de Ponte de Lima (séculos XVI a XIX)", Bracara Augusta, vol. 50, n. 104-105, Braga, 2001-2002, p. 441-468. Para Espanha, cf., por exemplo, Miguel Luis López Muñoz, La labor benéfico-social de las Cofradías en la Granada Moderna, Granada, Universidade de Granada, 1994, p. 36-56.
} 
Tabela 3. Receitas e despesas (em réis) da Irmandade (1806-1820)

\begin{tabular}{|c|c|c|c|c|c|c|c|c|}
\hline Ano & Receita & Despesa & Saldo & $\begin{array}{l}\text { Receita } \\
\text { do Cofre } \\
\text { dos } \\
\text { Pobres }\end{array}$ & $\begin{array}{c}\text { Despesa } \\
\text { do Cofre } \\
\text { dos } \\
\text { Pobres }\end{array}$ & $\begin{array}{l}\text { Total de } \\
\text { receita }\end{array}$ & $\begin{array}{l}\text { Total de } \\
\text { despesa }\end{array}$ & $\begin{array}{c}\text { Percentagem } \\
\text { dos gastos } \\
\text { com os } \\
\text { pobres }\end{array}$ \\
\hline 306 & 1.265 .925 & 841.915 & 424.010 & 30.930 & 29.800 & 1.296 .855 & 871.715 & 3,4 \\
\hline 307 & 1.247 .520 & 1.044 .695 & 202.825 & 20.010 & 17.200 & 1.267 .530 & 1.061 .895 & 1,0 \\
\hline 1808 & 1.076 .395 & 883.450 & 192.945 & 23.610 & 18.800 & 1.100 .005 & 902.250 & 2,1 \\
\hline 1809 & 844.364 & 775.428 & 68.936 & 27.210 & 16.640 & 871.574 & 792.068 & 2,1 \\
\hline 1810 & 916.810 & 755.595 & 161.215 & 29.210 & 20.120 & 946.020 & 775.715 & 2,6 \\
\hline 811 & 923.210 & 780.155 & 143.055 & 35.320 & 26.240 & 958.530 & 806.395 & 3,3 \\
\hline 1812 & 1.011.621 & 760.550 & 251.071 & 34.290 & 24.720 & 1.045.911 & 785.270 & 3,1 \\
\hline 1813 & 1.066 .687 & 810.724 & 255.963 & 29.490 & 25.760 & 1.096 .177 & 836.484 & 3,1 \\
\hline 1814 & 1.066 .273 & 848.785 & 217.488 & 30.610 & 29.920 & 1.096 .883 & 878.705 & 3,4 \\
\hline 1815 & 1.217 .338 & 1.067 .745 & 149.593 & 34.605 & 26.800 & 1.251 .943 & 1.094 .545 & 2,4 \\
\hline 1816 & 1.061 .303 & 921.907 & 139.396 & 40.285 & 28.560 & 1.101 .588 & 950.467 & 3,0 \\
\hline 1817 & 1.425 .606 & 1.050 .395 & 375.211 & 34.525 & 33.600 & 1.460 .131 & 1.083 .995 & 3,1 \\
\hline 1818 & 1.446 .791 & 1.236 .314 & 210.477 & 22.045 & 30.240 & 1.468 .836 & 1.266 .554 & 2,4 \\
\hline 1819 & 824.645 & 758.059 & 66.586 & 11.600 & 12.400 & 836.245 & 770.459 & 1,6 \\
\hline 1820 & 738.576 & 719.616 & 18.960 & 17.280 & 17.120 & 755.856 & 736.736 & 2,3 \\
\hline Total & 16.133 .064 & 13.255 .333 & 2.877 .731 & 421.020 & 357.920 & 16.554 .084 & 13.613.253 & 2,6 \\
\hline
\end{tabular}

Fonte: elaborado com base nos livros de receita e despesa da Irmandade. Cf. Lisboa, Arquivo Histórico do Patriarcado de Lisboa, PLSB36/ISS/3O/016, fls. 98-121; PLSB36/ISS/3O/018, fls. 27-65 e PLSB36/ISS/3O/017, fls. 83-116.

Entre 1806 e 1820, as petições de pobres ascenderam a 294. Contudo, nove referiram-se a esmolas concedidas aos andadores, ${ }^{48} 30$ não são mais do que solicitações para passar a ficar assente no livro dos pobres e pedidos para não

\footnotetext{
${ }^{48}$ No período em estudo, os andadores eram José Caetano do Amaral e Bento José dos Santos. A 12 de maio de 1816, decidiu-se que o andador José Caetano de Amaral ficaria a ganhar de ordenado 40 mil réis, além de ter direito a ocupar uma casa, enquanto Bento José dos Santos receberia 30 mil. A partir de então, não pediriam à Mesa ajudas de custo. Tinham como obrigação andar às semanas e às propinas que seriam repartidas entre ambos. O primeiro deveria acompanhar o Santíssimo todas as vezes que saísse, mas o segundo estava dispensado dessa tarefa. Só deveria acompanhar o Santíssimo à noite com obrigação de o peditório da freguesia ser repartido por ambos. Cf. Lisboa, AHPL, PLSB36/ISS/O3/004, fl. 52. Em breve, o primeiro andador, José Caetano do Amaral, será despedido "para nunca mais poder servir nesta irmandade por se achar culpado em todo o capítulo do nosso compromisso relativo aos andadores", segundo decisão de 10 de julho de 1821 . Cf. Ibidem, fl. 55. Ora, no capítulo 17 do compromisso, relativo aos andadores, observa-se que se dava preferência aos homens que soubessem ler e escrever, ao mesmo tempo em que se informa acerca das funções dos andadores: "§ 2 obrigados a assistir continuamente na igreja com capa na qual trará sempre a medalha do Santíssimo, terá muito cuidado no asseio do altar ou capelas em que estiver colocado o Santíssimo Sacramento, em que as alfaias estejam nos seus lugares competentes e com toda a limpeza e bem acondicionadas logo que se der o primeiro repique para sair o Santíssimo Sacramento, acudirá logo à igreja a aprontar tudo quanto for preciso para este ato sem que nisso tenha a menor dúvida ou descuido, irá adiante com algumas tochas para algum irmão que se encaminhe para acompanhar ou para suprir alguma que se quebrar havendo dois andadores ficará o outro na igreja enquanto se não recolher o Santíssimo. § 3 Terá grande obediência à Mesa executando tudo quanto por ela Ihe for ordenado, darão parte todos os dias ao irmão procurador da Mesa de tudo quanto se passar na igreja, tanto de batizados como de outra qualquer ação que se deverá participar à Mesa e vagando o lugar de primeiro andador se dará acesso ao segundo, sendo capaz. § 4 Conhecendo-se que não cumprem com as suas obrigações ou que tem algum vício ou má conduta, não sendo grave, serão repreendidos, a primeira vez pelo procurador da Mesa e pela segunda dará o mesmo procurador parte à Mesa para que informada da verdade despeça o andador, terá casas ao pé da igreja e de ordenado em cada ano o primeiro 30.600 o segundo 24.000". Cf. Idem, PLSB36/ISS/O1/O03. Ou seja, em conclusão, o andador deposto, que havia sido admitido a 8 de setembro de 1796, em substituição de Joaquim Pedro, deposto a 4 de setembro do mesmo ano, deixara de cumprir as suas obrigações e conhecera o mesmo destino do seu antecessor. Cf. Ibidem, PLSB36/ISS/O3/004, fls. 36-36v.
} 
pagar as presidências, 30 reportaram-se a um legado que não privilegiou os confrades e as restantes 225 é que, efetivamente, constituíram pedidos de auxílio monetário por parte dos membros da confraria. Nesses casos, as esmolas variaram bastante, entre um mínimo de 800 e um máximo de 6.400 réis. A média ficou nos 1.450 réis por esmola. Essas 225 esmolas beneficiaram 180 mulheres, todas viúvas, e 45 homens, três dos quais casados. No entanto, não estivemos perante 225 pessoas diferentes. Nesse universo, as referidas ajudas foram atribuídas a 51 pessoas, importando notar que 31 receberam mais do que uma esmola ao longo dos anos. Nesse caso, pontificaram mais uma vez as mulheres viúvas, nomeadamente oito que receberam de 10 a 20 esmolas entre 1806 e 1820. Esse tipo de informação é corroborado pelas anotações nas patentes. ${ }^{49}$

A casuística érica evariada, quer nas petições para isenção do pagamento das presidências, quer nas que se referiram à solicitação para integrar o rol dos pobres, quer ainda as que foram afetas ao recebimento de esmolas monetárias. Predominaram sempre as petições femininas, mas também se encontram as de alguns homens.

\section{As festas religiosas, em algumas confrarias, absorviam a quase totalidade das receitas}

Assim, se em 1810, a viúva Bernardina Teresa Rosa alegou estado de indigência para justificar as presidências em atraso e ser admitida como pobre, ${ }^{50}$ o mesmo fez uma outra viúva, dois anos depois, justificando ter ficado muito "aleanada" após a morte do marido, acrescentando as "adversidades do tempo", uma eventual alusão às consequências nefastas das invasões francesas. ${ }^{51}$ No que se refere aos homens, por exemplo, em 1808, António Francisco, casado com Rosa Teresa, solicitou a isenção do pagamento das presidências alegando ter "em sua caza algumas tres camas com peçoas padecendo o grande mal de malignas não tendo o supplicante meios suficientes para se poder alimentar muito menos para acudir as ditas moléstias vendo ce por isso em situação". ${ }^{2}$

$\mathrm{O}$ ano de 1814 foi particularmente proveitoso em esmolas. De fato, entre as receitas desse ano, contou-se o legado de João António Vitorino, o qual deveria ser distribuído entre mulheres pobres, solteiras, casadas ou viúvas. Não se sabe se foi um legado em vida ou deixado em testamento, embora pareça mais plausível a segunda hipótese, pois algumas das suplicantes aludiram ao fato de o benfeitor estar morto. ${ }^{53}$ A notícia dessa esmola correu célere, pois 30

\footnotetext{
49 Lisboa, AHPL, PLSB36/ISS/05.

50/bidem, PLSB36/ISS/39, doc. 45.

$51 /$ bidem, doc. 46.

52/bidem, PLSB36/ISS/13, doc. 45.

${ }^{53}$ No livro de receita da irmandade, apenas consta o legado. Cf. Ibidem, PLSB36/ISS/3O/O18, fl. 51v. O arquivo não guarda testamentos daquela data.
} 
mulheres pediram e, pelo menos, 23 receberam 2.352 réis cada uma, num total de 54.096 réis, ou de 70.560 réis, se todas foram contempladas. Nesses casos, foi comum as mulheres pedirem para si - alegando pobreza, doença, existência de filhas donzelas ou de filhos menores - ou solicitarem esmola para suas filhas donzelas. Na maioria das petições -25 de viúvas, três de solteiras e duas de casadas - , pode-se ler alusões ao fato de viverem com todo o recolhimento ou de serem de louvável procedimento, atestando como testemunha o pároco. Tenhamos em conta que, entre as características que definiam a mulher digna e honrada, contavam-se a gravidade, a sisudez, a modéstia, o recato e, naturalmente, a virgindade, tanto mais que a honra feminina dependia do comportamento sexual. ${ }^{54}$ Assim se compreendem as propostas educacionais pensadas para o sexo feminino ao longo de toda a Época Moderna. ${ }^{55}$ Por outro lado, tal como acontecia com as dotadas, como escreveu Maria Antónia Lopes, a criação de dotes tornou visível os objetivos da assistência, "não o socorro à indigência económica mas a prevenção da indigência moral. Se se actua financeiramente, se se acode à miséria económica é só porque esta conduz à miséria morall. ${ }^{56}$ Ou seja, visava-se ao controle rigoroso dos comportamentos femininos através de um mecanismo econômico, o que estava bem interiorizado por parte de todos, inclusivamente por parte dessas mulheres que solicitavam esmola. Afinal, o debate acerca da seleção de pobres de acordo com o seu comportamento motivou intervenções quer entre leigos quer entre homens da Igreja. ${ }^{57}$

Alguns exemplos tornam mais clara a situação. Na petição de Inácia Maria, viúva de Jerónimo de Sousa, pode ler-se:

tem notícia que o falecido João António Vitorino que Deus tenha em glória deichou esmolas para as viúvas emtrevadas e como a suplicante he pobre e com tres filhos vivendo tãobem de esmolas cerconstancia que se faz merecedora de que vossa mercê haja compaichão com a supplicante com ser huma do numero das protegidas..$^{58}$

\section{Antónia Joaquina fez saber que}

ella suplicante por falescimento do dito seu marido ficou vivendo pobremente não tendo outros meios mais do que o trabalho de sua custura, que este por limitado lhe não chega assim e experimenta necessidades rezedindo porem com recolhimento e honestidade o que faz certo por pella informação do reverendo parocho desta freguezia. ${ }^{59}$

\footnotetext{
${ }^{54}$ Maria Antónia Lopes, Mulheres, espaço e sociabilidade. A transformação dos papéis femininos em Portugal à luz das fontes literárias (segunda metade do século XVIII), Lisboa, Livros Horizonte, 1989, p. 21-25; 174-178. ${ }^{5}$ Isabel M. R. Mendes Drumond Braga, "A educação feminina em Portugal no século XVIII: tradição ou inovação", In: _. . . Cultura, religião e quotidiano. Portugal: século XVIII, Lisboa, Hugin, 2005, p. 135-163. ${ }^{56}$ Maria Antónia Lopes, Pobreza, assistência e controlo social. Coimbra (1750-1850), vol. 1, Viseu, Palimage Editores, Centro de História da Sociedade e da Cultura, 2000, p. 805. ${ }^{5}$ Ibidem, p. $74-78$.

58Lisboa, AHPL, PLSB36/ISS/13, doc. 128.

59/bidem, doc. 143.
} 
Isabel Maria, outra viúva, afirmou que "se acha vivendo no maior desamparo sem ter ninguém de que se possa valer se não dos benfeitores que lhe fazem bem como o pode attestar o reverendo parocho da sua mesma freguezia" ${ }^{60}$ Por seu lado, Maria Teodora, solteira e órfã de pai, declarou que "vive com ostinadade [sic] recolhida muito pobre pois pella emvasão dos francezes ficou sem coiza nenhuma vivendo dos fieis de Deus". ${ }^{61}$

A pobreza motivava mulheres e homens a pedir esmola, alegando, sobretudo, a viuvez, a velhice, a doença ou o fato de não poderem trabalhar por qualquer outro motivo. Se tivermos em conta a tipologia de pobres referida por Jean-Pierre Gutton, ${ }^{62}$ isto é, doentes, velhos e viúvos, podemos verificar que, no universo em estudo, estamos perante um grupo de pessoas viúvas, idosas, doentes e, consequentemente, sem capacidades físicas para trabalhar, sendo verdade que, na maior parte dos casos, foram alegados mais do que um motivo para a pobreza ou simplesmente a indicação de que eram pobres sem acrescento dos motivos para se encontrarem em tal situação.

\section{O número de beneficiários de esmolas variou muito ao longo dos anos, havendo pessoas que foram contempladas em diversos anos sucessivos}

Vejamos alguns exemplos. Entre as mulheres, alegar pobreza sem esclarecer o motivo foi comum. Tomásia Joaquina, na petição que endereçou à confraria, afirmou que "se acha vivendo em suma pobreza sem meios de se poder alimentar e a hum filho que tem sete mezes doente". ${ }^{63}$ Justina Teresa não fugiu ao mesmo tipo de discurso

em virtude da sua pobreza e indigência tem sido socorrida pela Meza desta mesma irmandada e como prezentemente se acha em lastimozo estado não só de pobreza mas tãobem de gravíssimas moléstias que padece e pelas quaes sofre as maiores necessidades como he constante e notório. ${ }^{64}$

Em outros casos, foi alegada a viuvez como causa direta da pobreza. Por exemplo, Teresa da Piedade fez saber que "por falescimento de seu marido ficou vivendo muito pobremente faltando-lhe os meios para se poder sustentar e a hum filho que tem demente". ${ }^{65}$ D. Josefa Barbosa

\footnotetext{
60Lisboa, AHPL, PLSB36/ISS/13, doc. 148.

6lbidem, doc. 149.

62/bidem, doc. 149 .

63/bidem, doc. 1. Sobre doenças infantis, cf. Hugh Cunningham, Children \& childhood in Western society since 1500, Londres, Longman, 1995, p. 111-117; Patricia Crawford, Parents of poor children in England: 1580-1800, Oxford, Oxford University Press, 2010, p. 127-129.

${ }^{64}$ Lisboa, AHPL, doc. 2.

65/bidem, doc. 5.
} 
ficou muito pobre por morte de seu marido na companhia de dois filhos não tendo rendimento algum mais que o seu travalho das suas mãos de que vive e agora de presente empessebilitada do mesmo por cauza de huma grave molestia que padece. ${ }^{66}$

Já Tomásia Joaquina alegou a falta do genro: "vive muito pobremente tendo em sua companhia huma filha sega e netos menores, tendo seu genro auzente sem nada lhe deixar para seu sustento o que he bem constante".67

A viuvez, em conjunto com a doença, também foi alegada por Joana Barbosa de Freitas:

que ficando por falecimento se seu marido muito pobre e sem meios alguns para se poder sustentar mais que o piqueno travalho de suas mãos que lhe não chega para suprir a sua grande necessidade que actualmente esta pedecendo junto com huma grave doença de peito que mal pode exercitar mesmo pouco trabalho. ${ }^{68}$

Naturalmente, a doença per si foi objeto de menção de forma recorrente. Por exemplo, Joana Barbosa Perpétua de Freitas fez saber que "além de padecer actualmente moléstia experimenta necesidades pela sua muita pobreza rezedindo com recolhimento e bom procedimento o que tudo he bem constante", ${ }^{69}$ enquanto D. Maria Joaquina das Necessidades esclareceu que "se acha entrevada vivendo pobremente na companhia de hua sua criada a cuja se anda valendo de fieis de Deus para a poder alimentar."70 Além disso,

se acha vivendo muito pobremente e entrevada em hua cama e agora proximamente se vio em perigo de vida sacramentada e ungida na companhia de hua sua criada que foi a qual pelosfieis de Deus adquire alguma cousa que pode para o seu alimento com muito custo. ${ }^{71}$

E, em outra petição,

se acha entrevada em hua cama a huns poucos de annos a agora a des dias que lhe deo de novo hum ar de estupor do qual espera hir dar contas ao altíssimo mas como se acha sem ter meios alguns para se poder alimentar se não de alguma esmola que pelos fieis de Deus lhe podem adquirir. ${ }^{72}$

Tomásia Joaquina "além de se achar doente não tem meios com que se poça sustentar tanto assim que esta em caza de huma filha cazada que a recolhe pello amor de Deos" ${ }^{73}$ Repare-se que, num dos casos em análise, a autora da petição ostenta o título de dona e refere viver com uma criada, indícios claros de que já conhecera uma posição melhor.

\footnotetext{
66 Lisboa, AHPL, PLSB36/ISS/13, doc. 114

67/bidem doc 118

68 lbidem, doc. 166

69/bidem, doc. 32

70/bidem, doc. 33 .

"71/bidem, doc. 51.

72 bidem, doc. 76 .

33lbidem doc 165
} 
As mulheres, ao alegarem idade avançada, preferiram, majoritariamente, referir-se ao fato de forma eufemística. Joaquina Baptista disse "se achar em crecida idade" e "avultada em anos", ${ }^{74}$ enquanto Maria Joaquina alegou "avultada idade".75 De qualquer modo, Josefa Maria de Campos afirmou ter mais de 80 anos $^{76}$ e Josefa Maria tornou claro ser senhora de mais de 90 anos. ${ }^{77}$

No grupo masculino, as situações referidas não foram muito diferentes. Em 1813, Bernardo José Moreira fez saber que necessitava de esmola porque a sua mulher estava gravemente doente e, consequentemente, faltavam-lhe meios para a socorrer. ${ }^{78}$ No mesmo ano, Simplício Xavier alegou um dos princípios base da pobreza, o laço entre falta de trabalho e pauperismo: "se acha gravemente molesto com huma molestia imterior que o priva de trabalhar por cauza della tem gasto grande quantia e como vive de seu jurnal que não tem outro meio se acha mais sem ter mais que possa gastar".79

Por seu lado, em 1815, Joaquim José Franco foi admitido na categoria de pobre por ser idoso e "entrevado", enquanto José Pinto Malheiro alegou a idade avançada; ${ }^{81}$ consequentemente, ambos eram pobres por não poderem trabalhar. A doença foi igualmente uma das causas citadas por António Ferreira: "se acha muito doente deitando sangue pella boca faltando-lhe os meios para se poder tratar"."2 Por seu lado, Manuel Lourenço fez saber que "tem tido huma molestia porlongada e nella se tem detriorado e se ve em precizão não tendo com que se poça ao menos alimentar sua molher e duas filhas menores",83 enquanto José Caetano de Amaral Andrade fez notar "como prezentemente se acha em huma cama com huma catarral maligna assistido do medico com tantas garrafas de remédios de sorte que se não acha com meios para poder suprir a sua moléstia".84

Por vezes, os suplicantes indicaram as idades: António José de Carvalho alegou ter 73 anos, em 1816, além de estar "quebrado", sem poder trabalhar pela idade e pela moléstia. Em 1809, declarou servir a irmandade há 27 anos e, em 1810, ser irmão há 48 anos. ${ }^{85}$ Joaquim Manuel Pereira também aludiu à idade, no caso, 83 anos. $^{86}$

Em suma, o leque de motivos apontados é maior nas mulheres do que nos homens. Estes, de um modo geral, indicaram doença ou avançada idade que os impedia de trabalhar, enquanto as petições femininas recorreram à viuvez, à velhice, à doença e à existência de vários filhos menores, alguns dos quais doentes. Em muitas petições, alegou-se mais do que uma causa, enquanto, em outras, referiu-se apenas a situação de pobreza, sem aduzir os motivos para a situação.

\footnotetext{
74Lisboa, AHPL, PLSB36/ISS/13, doc. 11 e doc. 35

75/bidem, doc. 19.

${ }^{76} / \mathrm{bidem}$, doc. 93

"IIbidem, doc. 70

78/bidem, doc. 107.

79/bidem, doc. 110

80/bidem, doc. 176

31/bidem, doc. 177.

s2/bidem, doc. 30.

${ }^{83} \mathrm{lbidem}$, doc. 86

84/bidem, doc. 180.

85/bidem, docs. 60, 81 e 197

86/bidem, doc. 243.
} 
Tentemos sintetizar as respostas às perguntas formuladas inicialmente. Entre 1806 e 1821, a confraria do Santíssimo Sacramento de Santo Estêvão, em Alfama, prestou auxílio monetário a 51 membros, com destaque para as viúvas dos irmãos, que se abstiveram de contrair segundas núpcias. Os 51 beneficiados auferiram 225 esmolas, o que nos dá uma média de 4,4 esmolas por pessoa. Tal fato, como antes se verificou, esconde sérias assimetrias, na medida em que oito pessoas beneficiaram de dez a 20 esmolas nos anos em estudo, sendo recebedoras de mais do que uma ajuda monetária por ano.

\section{A pobreza motivava mulheres e homens a pedir esmola, alegando, sobretudo, a viuvez, a velhice, a doença ou o fato de não poderem trabalhar por qualquer outro motivo}

A documentação não nos fornece, a não ser residualmente, dados relativos às áreas profissionais dos confrades. Porém, cremos não estar longe da verdade se presumirmos estar perante uma maioria de homens ligados às profissões marítimas, a par de alguns eclesiásticos e de um ou outro homem afeto à vida militar. Consequentemente, as viúvas, mesmo as que se dedicavam à costura ou a atividades similares, após terem perdido o marido, a fonte de receitas mais relevante, ficavam em situação de indigência agravada pelo fato de serem idosas, doentes ou de terem vários filhos a seu cargo. A existência de filhas solteiras, nesses fogos femininos, era inclusivamente uma outra preocupação frequentemente lembrada. Se algumas confrarias possuíam hospitais e se outras concediam dotes para casamento de donzelas, não era o caso da de Santo Estêvão de Alfama, o que limitava a ajuda material à esmola monetária. A exceção foi pontual, no ano de 1814, quando um legado, destinado a mulheres carenciadas, independentemente de serem ou não confreiras e de serem casadas, solteiras ou viúvas, foi distribuído.

A pobreza foi, nesse como em outros universos, apanágio majoritariamente feminino. As esmolas distribuídas pela confraria a esses 51 homens e mulheres foram certamente muito relevantes para fazer face às dificuldades quotidianas desses pobres. Porém, não podemos deixar de notar que a irmandade se preocupava ou pelo menos investia bem mais no culto e no apoio espiritual do que no apoio material. As festas celebradas na Semana Santa e no dia do Corpo de Deus - a par do acompanhamento dos defuntos e das missas por alma dos falecidos confrades e de suas esposas - eram, a avaliar pelos gastos, ou seja, pela prática assistencial efetiva, os verdadeiros fundamentos dessa confraria, como de tantas outras. 